\title{
Manajemen Pendidikan Khusus di Sekolah Luar Biasa Untuk Anak Autis
}

\author{
Gangsar Ali Daroni \\ Pendidikan Luar Biasa, Pascasarjana Universitas Sebelas Maret Surakarta \\ gangsaralidaroni@gmail.com \\ Gina Solihat \\ Pendidikan Luar Biasa, Pascasarjana Universitas Sebelas Maret Surakarta \\ solihatgina@gmail.com \\ Abdul Salim \\ Pendidikan Luar Biasa, Pascasarjana Universitas Sebelas Maret Surakarta \\ salimchoiri@fkip.uns.ac.id
}

\begin{abstract}
This study aims to determine the implementation of special education management at Special School for Autism. This research is descriptive qualitative research. The speakers in this research are the principal and two teachers at Special School for Autism in Karanganyar. Data were collected by interview, observation, and documentation. Data analysis techniques using Miles and Huberman models. There are three steps in this model, namely data reduction, data display, and conclusion. The implementation of special education management at Special School for Autism in coordination by a principal. In planning educational programs, tailored to the ability of each autistic student using IEP (Individual Educational Program). The school has an organizational structure that works in accordance with its duties. The principal is in charge of coordinating school management, while the teacher is responsible for the management of the class. Special School for Autism is a recently established school. The condition of autistic students who have different characteristics, the location of the foundation's office with the school is very far away, and the entry of students with different disorder conditions with autistic students makes the implementation of education management in Special School for Autism not running optimally. Therefore, schools have made efforts to minimize these barriers.
\end{abstract}

Keywords: Autism, Educational Management, Special School for Autism

\section{Article Info}

\section{PENDAHULUAN}

Pendidikan mempunyai tugas menyiapkan sumber daya manusia untuk pembangunan seirama dengan tuntutan zaman. Perkembangan zaman selalu memunculkan persoalan-persoalan baru yang tidak pernah terpikirkan sebelumnya (Noordyana, 2016). Suatu pendidikan dipandang bermutu diukur dari perannya untuk ikut mencerdaskan 196 kehidupan bangsa dan memajukan kebudayaan nasional adalah pendidikan yang berhasil membentuk generasi muda yang cerdas, berkarakter, bermoral dan berkepribadian (Haryono, 2015). Untuk itu perlu dirancang suatu sistem pendidikan yang mampu menciptakan suasana dan proses pembelajaran yang menyenangkan, merangsang dan menantang peserta didik untuk 
Manajemen Pendidikan Khsusus di SLB Autis Mitra Ananda Colomadu | Gangsar A. Daroni, dkk.

mengembangkan diri secara optimal sesuai dengan bakat dan kemampuannya (Mailani, 2018).

Perhatian pemerinah terhadap masalah pendidikan, pemerintah masih terasa kurang. Gambaran ini tercermin dari beragamnya masalah pendidikan yang makin rumit (Widodo, Waridin, \& Maria, 2011). Kualitas siswa masih rendah, pengajar kurang profesional, biaya pendidikan yang mahal, bahkan aturan Undang undang di bidang pendidikan masih terasa kacau. Dampak dari pendidikan yang buruk itu, negeri kita ke depannya makin terpuruk. Keterpurukan ini dapat juga akibat dari kecilnya rata-rata alokasi anggaran pendidikan baik di tingkat nasional, propinsi, maupun kota dan kabupaten (Mantja, 2016).

Penyelesaian masalah pendidikan tidak semestinya dilakukan secara terpisah-pisah, tetapi harus ditempuh langkah atau tindakan yang sifatnya menyeluruh (Wardani, 2017). Artinya, kita tidak hanya memperhatikan pada kenaikkan anggaran saja. Sebab percuma saja, jika kualitas sumber daya manusia dan mutu pendidikan di Indonesia masih rendah. Masalah penyelenggaraan wajib belajar sembilan tahun sejatinya masih menjadi PR besar bagi kita. Kenyataan yang dapat kita lihat bahwa banyak di daerah-daerah pinggiran yang tidak memiliki sarana pendidikan yang memadai (Hidayat, 2012). Dengan terbengkalainya program wajib belajar mengakibatkan anak-anak Indonesia masih banyak yang putus sekolah sebelum mereka menyelesaikan wajib belajar. Dengan kondisi tersebut, bila tidak ada perubahan kebijakan yang signifikan, sulit bagi bangsa ini keluar dari masalah-masalah pendidikan yang ada, apalagi bertahan pada kompetisi di era global (Maamarah, 2016). Berdasarkan uraian permasalahan diatas, maka dibutuhkan suatu solusi yang bisa mengatasinya. Salah satu solusi tersebut yaitu adalah diperbaikinya sistem manajemen pendidikan di satuan-satuan pendidikan (Wati, 2014).
Manajemen pendidikan adalah sebuah proses yang dilaksanakan secara sadar dan terencana untuk menciptakan suasana belajar dan proses pembelajaran serta mencapai tujuan pendidikan dimulai dari perencanaan, pengorganisasian, pelaksanaan dan pengawasan dengan menggunakan sumber daya manusia dan sumber daya yang lain untuk mencapai tujuan organisasi (Maria \& Sediyono, 2017). Fungsi pokok manajemen pembelajaran adalah perencanaan, pengorganisasian, kepemimpinan dan pengawasan (Sa'ud dan Sumantri dalam Maria \& Sediyono, 2017). Semua satuan pendidikan di Indonesia harus memiliki manajemen pendidikan yang baik tak terkecuali bagi sekolah luar biasa (SLB). Berbeda dengan satuan pendidikan regular, istilah manajemen pendidikan di sekolah luar biasa disebut dengan manajemen pendidikan khusus, yaitu manajemen sekolah untuk pelaksanaan pembelajaran bagi anak berkebutuhan khusus.

Anak berkebutuhan khusus (ABK) yaitu anak-anak yang menyandang kecacatan tertentu (disable children) baik secara fisik, mental dan emosional maupun yang mempunyai kebutuhan khusus dalam pendidikannya (children with special educational needs) (Suparno, 2007). Anak berkebutuhan khusus terbagi menjadi beberapa jenis ketunaan antara lain: tunanetra, tunarungu, tunagrahita, tunadaksa, tunalaras, dan autis.

Autis adalah kelainan perkembangan saraf kompleks yang ditandai dengan adanya masalah dalam interaksi sosial, komunikasi, minat terbatas, dan perilaku stereotip berulang (Siniscalco, Cirillo, Bradstreet \& Antonucci, 2013: 4261). Biasanya anak autis kurang minat untuk melakukan kontak sosial dan tidak adanya kontak mata. Selain itu, anak-anak autis memiliki kesulitan dalam berkomunikasi dan terlambat dalam perkembangan bicaranya. Ciri lainya nampak pada perilaku yang stereotype seperti mengepakkan tangan secara berulang- 
Kelola: Jurnal Manajemen Pendidikan, Vol. 5, No. 2, Juli-Desember 2018

ulang, mondar-mandir tidak bertujuan, menyusun benda berderet dan terpukau terhadap benda yang berputar dan masih banyak lagi ciri autis yang tak dapat disebutkan di sini karena setiap anak memiliki karakteristik yang berbeda-beda (Yuwono, 2012:15).

Di Indonesia, sekolah khusus bagi siswa autis disebut Sekolah Luar Biasa Autis. Salah satu sekolah khusus bagi siswa autis yaitu Sekolah Luar Biasa (SLB) Autis MAC yang berlokasi di kota Karanganyar, Provinsi Jawa Tengah. Di sekolah tersebut, disediakan layanan pendidikan dan terapi bagi siswa-siswi autis. Penanganan yang disesuaikan dengan kondisi anak, bertujuan untuk meningkatkan kemampuan yang dimiliki oleh masing-masing siswa autis. Keadaan siswa autis yang unik dan berbeda dengan siswa regular pada umumnya, menyebabkan penangannya memerlukan cara yang khusus, begitu pula dalam melakukan manajemen pendidikannya. Hal tersebut mendorong peneliti untuk mengetahui bagaimana manajemen pendidikan khusus di salah satu Sekolah Luar Biasa Autis di Kabupaten Karanganyar, Jawa Tengah.

\section{METODE PENELITIAN}

Penelitian ini merupakan penelitian deskriptif kualitatif. Penelitian ini dilakukan di Sekolah Luar Biasa Autis di Kabupaten Karanganyar. Narasumber dalam penelitian ini adalah kepala sekolah dan dua guru di SLB tersebut. Alat pengumpulan dalam penelitian ini menggunakan observasi, wawancara dan dokumentasi. Analisis data dalam penelitian ini, menggunakan Analisis Model Interaktif Miles dan Huberman. Ada tiga langkah pada model ini, yaitu reduksi data, tampilan data dan penarikan kesimpulan/ verifikasi. Reduksi data berarti meringkas, memilih poin penting, fokus pada masalah dan mencari temanya. Setelah dikurangi, langkah selanjutnya adalah menampilkan data. Langkah ketiga dalam menganalisa penelitian kualitatif adalah menarik kesimpulan atau verifikasi.
Kesimpulan dalam penelitian kualitatif adalah temuannya (Prakosa, Salim \& Sunardi, 2018: 58).

\section{HASIL PENELITIAN DAN PEMBAHASAN \\ Hasil Penelitian \\ Perencanaan Pendidikan}

Sekolah Luar Biasa Autis di Kabupaten Karanganyar, melakukan perencanaan pendidikan pada awal awal semester, setelah dilakukan asesman kemampuan anak oleh guru. Perencanaan dibuat di sekolah dengan melibatkan berbagai pihak. Setiap anak memiliki kondisi,kemampuan serta kebutuhan yang berbeda-beda. Hal ini yang mendasari diterapkannya IEP (Individual Educational Program) di Mitra Ananda. Di dalam IEP ini materi penanganan dimulai dari apa yang dapat dilakukan oleh anak. Program pembelajaran yang dikombinasikan dengan program terapi ditentukan setelah dilakukan serangkaian assessment / analisa kebutuhan yang melibatkan berbagai profesi yaitu dokter anak, psikolog/psikiater, guru dan terapis (fisioterapis, okupasi terapis, speech terapis).

Perencanaan program sekolah disusun oleh pengurus Sekolah Luar Biasa Autis di Kabupaten Karanganyar dan Yayasan dan sekolah menganggap bahwa perencanaan ini merupakan suatu hal yang penting karena sebagai pedoman untuk mencapai suatu tujuan pendidikan bagi siswa-siswi di Sekolah Luar Biasa Autis di Kabupaten Karanganyar, agar terprogram secara sistematis. Adapun rencana sekolah bagi peserta didik pada tahun ajaran 2017/2018 secara umum adalah sebagai berikut.
a. Tersusunnya Program Pendidikan Individual (PPI) untuk setiap siswa
b. Melaksanakan kegiatan belajar mengajar secara invidual dan klasikal
c. Melaksanakan kegiatan terapi sebagai penunjang keberhasilan program pendidikan/belajar siswa


Manajemen Pendidikan Khsusus di SLB Autis Mitra Ananda Colomadu | Gangsar A. Daroni, dkk.

d. Melaksanakan kegiatan ekstra kurikuler sekolah dalam bentuk pendidikan kesenian Tari dan melukis

e. Melaksanakan kegiatan ekstra kurikuler sekolah dalam bentuk pendidikan kesenian Tari dan melukis

f. Melaksanakan bimbingan ketrampilan hidup sehari-hari

g. Melaksanakan kegiatan 'Outing” / Familiy Gathering untuk melatih anak mengenal lingkungan dan sosialisasi dalam bentuk rekreasi bersama

h. Melaksanakan kegiatan ujian Tengah Semester (UTS) / dan Ujian semester serta ujian Akhir semester kenaikan kelas

i. Menyelenggarakan Sarasehan/Seminar orangtua anak berkebutuhan khusus

j. Menyelenggarakan kegiatan Pameran hasil Karya anak

k. Menyelenggarakan Workshop peningkatan SDM bagi tenaga Guru dan terapis

1. Mengirimkan guru untuk mengikuti kegiatan seminar dan pelatihan yang relevan dengan ketugasannya

m. Menyelenggarakan/Mengikuti kegiatan peringatan hari Penyandang cacat Internasional (HIPENCA)

n. Pembuatan Ruang terapi musik dan pembenahan administrasi sekolah.

Perencanaan pembelajaran dievaluasi dalam jangka 3 bulan sekali dan 6 bulan sekali oleh guru dan terapis. Perencanaan program sekolah disesuaikan dengan kurikulum dan kebutuhan pendidikan siswa, dan dievaluasi setiap satu tahun sekali.

\section{Pengorganisasian}

Guna menjalankan fungsi pengorganisasian, maka terdapat struktur organisasi yang terbentuk di Sekolah Luar Biasa Autis di Kabupaten Karanganyar. Sekolah Luar Biasa ini, merupakan Sekolah yang berada dibawah naungan Yayasan Swasta. Selain itu terdapat perkumpulan orang tua siswa yang bernama POSMA (Perkumpulan Orang tua Siswa Mitra Ananda). Perkumpulan ini bertujuan untuk mempererat silaturahmi antar orang tua siswa di Sekolah Luar Biasa Autis di Kabupaten Karanganyar dan mempermudah komunikasi antara orang tua siswa dengan sekolah terakit dengan pelaksanaan pembelajaran bagi siswasiswi di sekolah.

Struktur Kepengurusan Sekolah Luar Biasa Autis di Kabupaten Karanganyar terdiri dari: (a) Ketua Yayasan, (b) Kepala Sekolah, (c) Tata Usaha, (d) Bendahara Sekolah, (e) Wakil Kepala Sekolah, (f) Guru / Terapis. Adapun masing-masing fungsi dari setiap stuktur organisasi yaitu sebagai berikut.

a. Kepala sekolah melakukan kegiatan managerial sekolah, sebagai pemimpin di sekolah.

b. Wakil Kepala Sekolah: Membantu kepala sekolah melaksanakan kegiatan managerial sekolah.'

c. Bendahara: Mengelola keuangan di sekolah.

d. Tata Usaha: Menjadi Operator Sekolah dan pelaksana teknis penyelenggaraaan sistem administrasi dan informasi pendidikan di sekolah

e. Guru dan terapis: Melaksanakan pembelajaran dan terapi bagi siswa-siswa di sekolah.

f. Agar dapat melaksanakan organisasi dengan harmonis dan baik, cara sekolah mengatur organisasi yaitu dengan cara bekerja secara professional sesuai dengan tanggung jawabnya masing-masing, melakukan rapat rutin setiap sebulan sekali untuk melakukan evaluasi kerja. Kepala sekolah berperan sebagai pengatur organisasi agar dapat berjalan dengan harmonis dan baik. Apabila terjadi suatu konflik, sekolah menanganinya dengan cara melakukan musyawarah bersama.

\section{Pelaksanaan Pendidikan}

Fungsi pelaksanaan pendidikan Sekolah Luar Biasa Autis di Kabupaten Karanganyar, dilaksanakan oleh guru dengan bantuan terapis. Menurut sumber, pelaksanaan pendidikan telah berjalan cukup baik, namun masih mengalami 
Kelola: Jurnal Manajemen Pendidikan, Vol. 5, No. 2, Juli-Desember 2018

kendala karena kurikulum yang diberikan oleh pemerintah merupakan Kurikulum 2013 yang menggunakan pendekatan tematik yang mengharuskan siswa aktif. Keharusan ini sulit sekali diterapkan pada anak autis di sekolah yang kebanyakan adalah siswa autis berat. Selain itu, kemampuan anak yang berbedabeda, membuat guru harus lebih kreatif dalam melakukan pembelajaran dikelas.

Pada tahun pelajaran 2017/2018 Sekolah Luar Biasa Autis di Kabupaten Karanganyar memiliki 2 jenjang sekolah yaitu SDLB dan SMPLB dari kelas 1 sampai kelas 7. Kurikulum yang digunakan adalah kurikulum 2013. Namun dalam pelaksanaanya, kurikulum 2013 sulit diterapkan bagi anak autis di sekolah, karena hampir semua anak autis di sekolah ini tergolong kedalam autis berat. Oleh karena itu pembelajaran disesuaikan dengan kemampuan siswa melalui Program pembelajaran individual (PPI).

Mata pelajaran yang dilaksanakan terbagi menjadi 3 kelompok mata pelajaran yaitu:

a. Kelompok Akademik: Pendidikan agama dan budi pekerti, PPKN, Bahasa Indonesia, Matematika, IPA, IPS, Pendidikan Jasmani, olahraga dan kesehatan.

b. Kelompok Ketrampilan: Seni budaya dan ketrampilan dan Bina Diri.

c. Kelompok Kebutuhan Khusus: Sensori Motorik, Bicara dan komunikasi, Ketrampilan social

Selain itu, muatan lokal yang diajarkan adalah bahasa jawa dan pendidikan lingkungan hidup.

Tabel 1. Karakteristik siswa

\begin{tabular}{cc}
\hline Jenis Ketunaan & Jumlah Siswa \\
\hline Autis & 19 \\
\hline Cerebral Palsy & 6 \\
\hline Down Syndrom & 3 \\
\hline ADHD & 2 \\
\hline Kelainan Ganda & 2 \\
\hline Total & 32 \\
\hline
\end{tabular}

Tabel 2. Jadwal kegiatan sekolah

\begin{tabular}{ll}
\hline \multicolumn{1}{c}{ Kegiatan } & \multicolumn{1}{c}{ Waktu } \\
\hline Pembelajaran & $08.30-12.00 \mathrm{WIB}$ \\
\hline Snack Time & $09.30-10.00 \mathrm{WIB}$ \\
\hline Pembelajaran & $10.00-11.30 \mathrm{WIB}$ \\
\hline Makan siang & $11.30-12.00 \mathrm{WIB}$ \\
\hline Pulang & $12.00 \mathrm{WIB}$ \\
\hline
\end{tabular}

Sekolah Luar Biasa Autis di Kabupaten Karanganyar memiliki kelas kelompok. Dalam kelas kelompok ini siswa belajar dalam satu kelas bersama yang dibatasi jumlah siswanya. Perbandingan guru dan siswa $2: 3$ atau 2:4. Hal tersebut bertujuan agar anak mendapatkan penanganan yang intensif dan optimal. Apabila terdapat siswa yang mengalami tantrum atau tidak bisa dikondisikan di kelas kelompok, makan siswa akan dibawa ke kelas transisi yang akan diberikan penanganan individual oleh guru. Selain kegiatan pembelajaran, terdapat kegiatan lain yaitu kegiatan terapi yang disesuaikan dengan kebutuhan siswa: (a) fisioterapi, (b) okupasi terapi, (c) hydroterapi, (d) terapi wicara, (e) snoezelen. Sedangkan kegiatan Extrakurikuler yaitu: (a) kelas musik, (b) kelas tari, (c) senam, (d) pramuka, (e) berenang.

Selain itu, dilaksanakan Outing class yang dilaksanakan setiap 3 bulan sekali. Kegiatan terapi dilakukan untuk memberikan pelayanan terapi untuk mengatasi hambatan anak yang bisa diatasi melalui pelayanan terapi seperti fisioterapi, okupasi terapi, terapi wicara, dll. Ekstrakurikuler dilaksanakan sebagai wadah anak untuk membekali anak melalui kegiatan-kegiatan yang dapat menyalurkan bakat anak agar dapat terasah dengan optimal dan sebagai sarana anak untuk bersosialisasi dengan lingkungannya (teman dan guru). Outing class bertujuan untuk memberi pengalaman nyata siswa untuk belajar di tempat kegiatan dan dapat bersosialisasi dengan masyarakat.

Kegiatan pembelajaran dapat mengoptimalkan kemampuan akademik siswa. Setelah dilakukan terapi, anak mengalami 
peningkatan dalam hal motorik, kemampuan bicara dan ketrampilan lainnya. Outing class membuat siswa menjadi lebih percaya diri ketika bersosialisasi.

\section{Pengendalian}

Pengendali dalam kegiatan KBM adalah kepala sekolah. Pengawas Sekolah Luar Biasa Autis di Kabupaten Karanganyar, yang ditunjuk oleh Dinas Pendidikan Khusus Provinsi Jawa Tengah. Selain itu, Ketua Yayasan juga melakukan kontroling terhadap SLB melalui rapat tahunan dan beberapa kunjungan. Kepala sekolah mengontrol pelaksanaan kegiatan belajar dan mengajar disekolah. Pengawas Sekolah, mengawasi pelaksanaan kegiatan pembelajaran di SLB agar sesuai dengan peraturan pemerintah provinsi jawa tengah. Ketua Yayasan melakukan pengawasan untuk mengetahui perkembangan dan kemajuan SLB Autis di Kabupaten Karanganyar agar semakin baik. Kepala sekolah melakukan monitoring setiap hari dan rapat bulanan. Pengawas melakukan monitoring dengan kunjungan kesekolah beberapa kali. Ketua Yayasan melalui rapat tahunan dan kunjungan. Kepala sekolah melakukan monitoring setiap hari dan rapat bulanan. Pengawas melakukan monitoring dengan kunjungan kesekolah beberapa kali..

\section{Evaluasi Pendidikan}

Manajemen kelas menjadi tanggung jawab guru. Setiap akhir pembelajaran, guru memberikan laporan kegiatan pembelajaran pada buku penghubung yang diberikan kepada orang tua. Hal terbut menjadi catatan perkembangan anak dan informasi kepada orang tua agar orang tua dapat membantu memaksimalkan program yang dilaksanakan disekolah dapat diterapkan juga di rumah.

Setiap 3 bulan sekali dan 6 bulan sekali guru dan terapis melaksanakan evaluasi program bagi siswa. Hal yang dirasa masih mengalami hambatan atau kekurangan, akan diperbaiki. Evaluasi yang dilakukan guru menggunakan aplikasi Therap yang digunakan khusus untuk mencatat setiap kegiatan dan perkembangan siswa dari akademik, terapi dan perkembangan lainnya seperti motorik, bina diri, perilaku dan lain-lain. Aplikasi ini sangat mudah digunakan, guru setiap harinya memasukkan data perkembangan siswa ditiap kegiatan yang mereka lakukan. Setelah itu setiap 3 bulan atau 6 bulan sekali, data itu akan terkumpul menjadi satu dalam dokumen yang berbentuk Microsoft Exel.

Dari data yang terkumpul, guru dapat melihat apa yang menjadi kekurangan dalam pelaksanaan pembelajaran bagi siswa seharihari selama ini, apa yang menjadi kebiasaan siswa yang perlu diubah dapat dilihat dan dievaluasi. Setiap satu bulan sekali kepala sekolah melalui rapat sekolah melakukan evaluasi kerja untuk menyelesaikan masalahmasalah atau kendala yang ada disekolah. Evaluasi tersebut menggunakan teknik diskusi yang membahas perkembangan dan masalah yang terjadi pada proses pembelajaran bagi siswa. Melalui POSMA setiap 3 bulan sekali, orang tua juga turut andil memberikan masukan kepada guru untuk kebaikan bersama. Melalui rapat tahunan yayasan, melakukan evaluasi managemen sekolah bersama pengurus yayasan.

Bagi sekolah, proses evaluasi penting karena semua evaluasi bertujuan untuk memperbaiki semua program dan manajemen sekolah sehingga membuat SLB Autis di Kabupaten Karanganyar menjadi lebih baik. Evaluasi dan masukan akan diterima dengan baik, dimusyawarahkan bersama, setelah diterima oleh forum, maka hal tersebut akan diperbaiki bersama. Evaluasi pembelajaran dilakukan oleh guru kemudian meminta pertimbangan dari terapis, psikolog dan ahli lain, kemudian disampaikan kepada orang tua terkait evaluasi belajar siswa agar orang tua juga dapat membantu menyelesaikan hambatan dalam pelaksanaan program bagi anak mereka. Sehingga pembelajaran akan berjalan dengan optimal. Evaluasi kepala sekolah dilakukan 
Kelola: Jurnal Manajemen Pendidikan, Vol. 5, No. 2, Juli-Desember 2018

melalui musyawarah pada rapat bersama seluruh struktur organisasi sekolah, dan diselesaikan pada forum tersebut. Evaluasi pengawas disampaikan kepada kepala sekolah. Evaluasi yayasan dilakukan melalui kunjungan dan rapat tahunan.'

\section{Faktor Pendukung dan Penghambat Pelaksanaan Pendidikan}

Faktor pendukung di SLB Autis di Kabupaten karanganyar yaitu sebagai berikut.

a. Sarana prasarana yang memadai

b. Banyak pihak yang mendukung evaluasi manajemen seperti kepala sekolah, pengawas, yayasan dan orang tua.

c. Pembiayaan sekolah yang cukup.

d. Dampak faktor-faktor tersebut pada sekolah yaitu sebagai berikut.

e. Sarana prasarana yang memadai sehingga memudahkan dalam pelaksanaan pendidikan di sekolah. Dalam pelaksanaan pembelajaran disekolah akan lebih mudah dengan adanya sarana prasarana yang memadai.

f. Banyak pihak yang mendukung evaluasi manajemen seperti kepala sekolah, pengawas, yayasan dan orang tua. Dengan banyak masukan dari berbagai pihak, maka pelaksanaan managemen di sekolah menjadi lebih baik.

g. Pembiayaan sekolah yang cukup. Pembiayaan yang cukup dapat mendukung pelaksanaan pembelajaran di sekolah menjadi lebih baik karena dalam pengadaan saran dan prasaran di sekolah membutuhkan dana yang tidak sedikit.

Selain faktor pendukung, terdapat beberapa hal yang menjadi penghambat pelaksanaan manajemen pendidikan di SLB Autis Mitra Ananda, yaitu:

a. Kondisi anak autis di SLB yang mayoritas berat, menyebabkan kurikulum 2013 tidak dapat sepenuhnya diterapkan.

b. Sekolah Luar Biasa ini merupakan sekolah yang belum lama berdiri, sehingga masih dalam tahap belajar dan merintis menjadi sekolah yang baik.

c. Yayasan yang memiliki kantor di Jakarta menyebabkan komunikasi secara langsung antara yayasan dengan sekolah menjadi sedikit terhambat.

d. Meskipun SLB Autis di Kabupaten Karanganyar ini merupakan SLB khusus Autis, namun masih menerima ketunaan lain seperti cerebral palsy, tunagrahita dan tunaganda. Hal tersebut dilakukan atas permintaan orang tua dan pertimbangan lain (dekat dengan rumah dan fasilitas terapi yang lebih lengkap).

e. Dalam mengatasi hambatan tersebut, sekolah telah melakukan upaya-upaya sebagai berikut:

f. Menggunakan program pembelajaran individual yang disesuaikan dengan kondisi anak.

g. Belajar berbenah diri untuk menjadi lebih baik, pembekalan ketrampilah guru melalui pelatihan-pelatihan (pelatihan menyusun PPi, pelatihan managerial, dll).

h. Kunjungan dengan yayasan dilakukan berkala.

i. Tetap menyarankan kepada orang tua agar anak ditempatkan di sekolah khusus sesuai ketunaannya, namun apabila masih tetap di SLB, sekolah akan memberikan program yang disesuaikan dengan kemampuan anak.

\section{Pembahasan}

Dari paparan hasil penelitin di atas dapat kita ketahui bahwa pelaksanaan manajemen pendidikan di sekolah luar biasa autis berbeda dengan pelaksanaan manajemen pendidikan di sekolah-sekolah lain. Karena pelaksanaan manajemen di lokasi penelitian ini berbea dengan temuan penelitian Yuliani, Suntoro, \& Kandar (2015), serta Helsa \& Hendriati (2017) yang menyebutkan bahwa manajemen pendidikan yang dilakukan guru di sekolah umum, dilakukan secara klasikal dengan jumlah siswa yang relatif banyak. Setiap rencana pembelajaran diperuntukkan 
Manajemen Pendidikan Khsusus di SLB Autis Mitra Ananda Colomadu | Gangsar A. Daroni, dkk.

untuk semua siswa tanpa adanya rencana pembelajaran individual.

Istiningsih (2005) juga menjelaskan pada sekolah inklusi memiliki kesamaan pada pelaksanaan pendidikan di sekolah regular, namun adanya guru pembimbing khusus yang membantu siswa untuk dapat berbaur dengan teman-temannya. Berbeda dengan sekolah lain, Sekolah Luar Biasa Autis di Kabupaten Karanganyar adalah sekolah khusus bagi anak autis, yang pelaksanaannya menggunakan caracara khusus untuk menyesuaikan diri dengan kemampuan yang dimiliki anak. Anak autis yang unik tentu perlu diberikan pelayanan yang lebih seperti pemberian terapi yang dapat memaksimalkan perkembangan anak.

\section{SIMPULAN DAN SARAN}

\section{Simpulan}

Berdasarkan temuan dan pembahasan hasil penelitian, dapat disimpulkan bahwa pelaksanaan manajemen pendidikan khusus di Sekolah Luar Biasa Autis di Kabupaten Karanganyar dikoordinasi oleh seorang kepala sekolah. Dalam merencanakan program pendidikan, disesuaikan dengan kemampuan masing-masing siswa autis menggunakan IEP (Individual Educational Program). Sekolah memiliki susunan organisasi yang berkerja sesuai dengan tugasnya. Kepala sekolah bertugas mengkoordinasi manajemen sekolah, sedangkan guru bertanggungjawab melakukan manajemen dikelas.

Sekolah Luar Biasa Autis di Kabupaten Karanganyar merupakan sekolah yang belum lama berdiri. Kondisi siswa autis yang memiliki karakteristik yang berbeda-beda, letak kantor yayasan dengan sekolah sangat jauh, dan masuknya siswa dengan kondisi ketunaan yang berbeda dengan siswa autis membuat pelaksanaan manajemen pendidikan di SLB tidak berjalan optimal. Oleh karena itu, sekolah telah melakukan upaya-upaya untuk meminimalisir hambatan tersebut.

\section{Saran}

Karakteristik siswa autis yang berbedabeda, mengharuskan guru untuk lebih kreatif dalam melakukan manajemen pendidikan dikelas agar siswa autis dapat mengikuti pembelajaran dengan baik. Masuknya siswa dengan kelainan/ketunaan yang berbeda dengan siswa autis karena kurang tersedianya sekolah khusus bagi ketunaan yang sesuai. Masalah jarak dan waktu menyebabkan orang tua menyekolahkan anaknya di sekolah autis. Oleh karena itu, pemerintah dapat menyediakan sekolah khusus yang dapat mengakomodasi semua ketunaan atau dapat menyediakan sekolah inklusi yang terjangkau di daerah sekitar colomadu, karanganyar.

\section{DAFTAR PUSTAKA}

Haryono, A. S. 2015. Evaluasi Pendidikan Inklusi Bagi Anak ABK di Provinsi Jawa Tengah. Jurnal Penelitian Pendidikan, 32(2), 119-126.

Helsa \& Hendriati, A. 2017. Kemampuan Manajemen Kelas Guru: Penelitian Tindakan Di Sekolah Dasar Dengan SES Rendah. Jurnal Psikologi, 16(2), 89-104.

Istiningsih. 2005. Manajemen Pendidikan Inklusi DiSekolah Dasar Negeri Klego 1 Kabupaten Boyolali (Tesis, Universitas Muhammadiyah Surakarta).

Hidayat, A.S. 2012. Manajemen Sekolah berbasis Karakter. Jurnal Inovasi dan Kewirausahaan, 1(1), 8-22.

Maamarah, S. 2016. Strategi Peningkatan Mutu dan Citra (Image) Sekolah Dasar Negeri Di Ungaran, Semarang. Kelola Jurnal Manajemen Pendidikan, 3(1), 115-130.

Mailani, E. 2018. Upaya Meningkatkan Hasil Belajar Matematika Pada Materi Pecahan Melalui Permainan Monopoli Pecahan. Jurnal Handayani PGSD FIP UNIMED, 4(1), 1-14. 
Kelola: Jurnal Manajemen Pendidikan, Vol. 5, No. 2, Juli-Desember 2018

Siniscalco, D., Cirillo, A., Bradstreet, J.J \& Antonucci, N. 2013. Epigenetic Findings in Autism: New Perspectives for Therapy. International Journal of Environmental Research and Public Health. 10, 4261-4273.

Suparno. 2007. Pendidikan Anak Berkebutuhan Khusus. Konsorsium Program S1 PGSD: Direktorat Jendral Pendidikan Tinggi.

Mantja, W. 2016. Manajemen Pendidikan Dalam Era Reformasi. Jurnal Ilmu Pendidikan, 7(2), 87-96.

Maria, E \& Sediyono, E. 2017. Pengembangan Model Manajemen Pembelajaran Berbasis TIK di Sekolah Dasar. Kelola Jurnal Manajemen Pendidikan, 4(1), 59-71.

Noordyana, M. A. 2016. Meningkatkan Kemampuan Berpikir Kritis Matematis Siswa melalui Pendekatan Metacognitive Instruction. Jurnal Pendidikan Matematika STKIP Garut, 5(2), 120-127.

Prakosa, D., Salim, A., \& Sunardi. 2018. The Implementation of Phonic Method in Teaching Vocabulary in Speaking to Visually Impaired Students in SLB A
(Visual Impairment). Journal of ICSAR. 2(1): $57-61$.

Wardani, K.W. 2017. Pengaruh Kreativitas dalam Peningkatan Kompetensi Kepemimpinan Alumni Magister Manajemen Pendidikan Pada Kurikulum Berbasis Kompetensi. Kelola Jurnal Manajemen Pendidikan, 4(2), 220-230.

Wati, E. 2014. Manajemen Pendidikan Inklusi

Di Sekolah Dasar Negeri 32 Kota Banda. Jurnal Ilmiah Didaktika, 14(2), 368-378

Widodo, A., Waridin, \& Maria, K. J. 2011. Analisis Pengaruh Pengeluaran Pemerintah Di Sektor Pendidikan Dan Kesehatan Terhadap Pengentasan Kemiskinan Melalui Peningkatan Pembangunan Manusia Di Provinsi Jawa Tengah. Jurnal Dinamika Ekonomi Pembangunan, 1(1), 25-42.

Yuliani, R., Suntoro, I, \& Kandar, S. 2015. Implementasi Manajemen Pendidikan Sekolah Dasar Negeri 1 Gisting Bawah. Jurnal Manajemen Mutu Pendidikan, 3(2).

Yuwono, J. 2012. Memahami Anak Autis (Kajian Teori dan Empirik). Bandung: Alfabeta. 